\title{
Violência, favela e pacificação: representações sobre a Unidade de Polícia Pacificadora no Morro do Andaraí do Rio de Janeiro
}

\section{Violence, slum and pacification: representations of the Pacifying Police Unit on Morro do Andaraí in Rio de Janeiro}

\author{
Gustavo Clayton Alves Santana* \\ Marcelo Henrique da Costa* \\ Ricardo Vieiralves de Castro***
}

\begin{abstract}
Resumo: As recentes medidas de ocupação policial praticadas pelo Governo do Estado do Rio de Janeiro, em 38 favelas da metrópole carioca, recolocam em discussão o controle através do qual o Estado age nestes territórios, desde sua configuração socioespacial. Partindo de uma abordagem holística, que considerou observar os fatos humanos como totalidades, foi desenvolvido um trabalho de campo exploratório e a aplicação de um questionário não diretivo a um conjunto de moradores do Morro do Andaraí, posteriormente as falas dos moradores foram tratadas segundo a técnica de análise de conteúdo. Percebe-se nas representações sociais dos moradores, o entendimento de que as ordens ideológica, política e econômica que compõem o Estado continuam a olhar as favelas como territórios onde identificam a desordem e a causa dos problemas sociais enfrentados pelo conjunto da cidade. Espaço que, por isso, precisa ser reordenado, "pacificado" para acabar com ideia da cidade partida em frações marginais.
\end{abstract}

Palavras-chave: Representações Sociais. Favelas. Rio de Janeiro.

\begin{abstract}
The recent police occupation measures applied by the government state of Rio de Janeiro in 38 slums put back in discussion the controlling acts used by the State in these territories since its socio spatial configuration. Starting from the holistic approach that considers the human facts as totality we develop an exploratory fieldwork and applied a nondirective questionnaire to a group residents of the Morro do Andaraí. The answers were analyzed according to the content analysis method. We perceive in the social representations of residents understanding that the ideological orders, political and economic that make up the State still look at the favelas as territories which identifies the clutter and the cause
\end{abstract}

\footnotetext{
"Doutorando em Sociologia Política na Universidade Estadual do Norte Fluminense Darcy Ribeiro (UENF); Mestre em Psicologia Social e Pesquisador do Laboratório de Estudos Contemporâneos da UERJ (Labore/UERJ).

"Professor Adjunto do Curso de Psicologia da Universidade Veiga de Almeida e Pesquisador do Laboratório de Estudos Contemporâneos da UERJ (Labore/UERJ).

***Professor Adjunto da UERJ e Coordenador do Laboratório de Estudos Contemporâneos da UERJ (Labore/UERJ).
} 
of the social problems facing the city sets. Space to be reordered, pacified to end that idea the broken city in marginal fractions.

Keywords: Social Representations. Slums. Rio de Janeiro.

Recebido em: 19/11/2015. Aceito em: 10/05/2016

\section{Introdução}

A tese do Brasil harmônico e homogêneo, ancorada em ideias como as da "brasilidade" (FREYRE, 2005), e da "cordialidade" (HOLANDA, 1995) - que buscam assinalar características positivas que estariam nas raízes de nossa constituição como nação - ainda hoje é exposta e reproduzida.

Apresentado como um país onde a cordialidade e a coesão social superam as desigualdades e abrem caminhos, o Brasil seria de fato o lugar onde se pode assumir uma identidade universal, onde os antagonismos de classe, raça e gênero se diluem.

Na relação do poder público com os territórios da pobreza e seus moradores, a tentativa de "pasteurizar" os antagonismos da sociedade brasileira através do "mito da brasilidade", do qual Freyre foi um profícuo propagador, por muito tempo logrou êxito em encobrir as desigualdades e, até os dias atuais, sua força pode ser percebida em certos "cuidados" de nossas elites em relação à explicitação de conflitos e diferenças (SOUSA, 2009).

Há que se levar em consideração que a propensa igualdade formal, centrada nos princípios culturais e nas representações comuns da nação, oculta a manutenção de formas sistêmicas de marginalização, pobreza e desrespeito exercidas cotidianamente para com aqueles cujos enunciados culturais, de classe social e processos históricos são colocados em condições de hierarquia e externalidade aos conteúdos das representações dominantes (DA SILVA, 2005). Como que escamoteadas, colocadas "para baixo do tapete", estas distinções não são afetadas pela proximidade geográfica ou pela interação cotidiana entre os distintos membros de cada grupo social, afinal por aqui impera a ordem do "cada qual com seu cada qual".
O papel hegemônico do Estado no monopólio legítimo dos símbolos culturais seja através da dominação institucional, do controle da violência e muitas vezes no exercício aberto da mesma no subjugo das minorias, especialmente, nas áreas pobres e de predomínio da empresa criminal do tráfico de drogas no Rio de Janeiro é um dos capítulos mais contundentes desta narrativa. Os moradores estão expostos a situações cotidianas de violência. Estes sujeitos carregam em si a marca de um processo histórico, que "entende" seus locais de moradia como espaço urbano desregulado, e esta representação negativa se concretiza principalmente na forma do alto índice de homicídios incluído da associação da imagem - sobretudo dos jovens - ao crime.

Diante deste cenário, a opção tomada para a constituição deste texto é trazer para o centro das discussões a forma através da qual os moradores de uma área pobre, especificamente denominada como uma favela ${ }^{1}$ da cidade do Rio de Janeiro, vivenciam e externam sua percepção da injustiça e lidam com a frustração de seus desejos e aspirações, quando confrontados com a atuação policial estatal.

Buscaremos, a partir da compreensão das representações sociais dos moradores a respeito de uma medida de policiamento de seu local de moradia, cotejar sentimentos e experiências empíricas, individuais e coletivas, de injustiça que estão expressas na relação cotidiana destes sujeitos com as instituições estatais, onde, em muitos momentos, predominam os maus tratos físicos, a privação de direitos e a submissão do corpo ao poder e ao arbítrio do outro (FOUCAULT, 2009).

Apontando o foco da pesquisa para a esfera pública atual vivenciada pelos moradores nos

\footnotetext{
${ }^{1}$ Neste texto, os termos favela, comunidade, territórios favelados ou territórios da pobreza, são utilizados como sinônimos para designar os locais de moradia da maioria dos pobres urbanos de nossas cidades.
} 
Violência, favela e pacificação: representações sobre a Unidade de Polícia Pacificadora ...

territórios favelados de uma das maiores metrópoles do país, o objetivo deste artigo é compreender quais representações estes sujeitos organizam para formular uma rede de relações entre seus membros e como estas representações estabelecem objetivos e procedimentos específicos para interpretar e pensar sua realidade cotidiana.

Tomada como ponto de referência, a metrópole carioca apresenta configurações sui generis na constituição contemporânea de suas favelas, onde a segregação residencial é erigida em referência às precariedades do mercado de trabalho e dos mecanismos de oportunidades de acesso ao capital social, "o que faz com que a pobreza urbana socialmente isolada se constitua como um caso paradigmático da exclusão social" (KAZTMAN, 2001, p. 173. Tradução livre).

Fato é que, nesta metrópole brasileira, a ocupação desordenada do solo urbano é uma das faces mais visíveis da estruturação do modo de produção capitalista, o qual gera uma extrema despossessão da renda da classe trabalhadora e uma consequente falta de acesso oficial à moradia, pois o custo de morar não está incluído no salário (MARICATO, 2007).

A geografia do Rio de Janeiro expõe a nódoa do processo de exclusão sócio territorial que sustenta esta cidade desde seu surgimento e que vem se intensificando a partir da consolidação das favelas na paisagem urbana. Ao longo do último século e, até os dias presentes, um intricado processo de condução das políticas públicas associado à estruturação social da cidade em benefício das classes mais abastadas, fez do Rio de Janeiro uma cidade escassa aos mais pobres.

Desta forma, as favelas são, efetivamente, ícones da capacidade de resistência que os mais pobres possuem na dura batalha cotidiana pela sobrevivência. Ao mesmo tempo, sua existência denuncia um extensivo sistema de omissão e debilidade do Estado brasileiro em prover as mais básicas políticas de moradia, saúde e educação.

\section{A Teoria das Representações Sociais e os estudos sobre favelas}

Objetivando discutir como tais questões se manifestam na esfera pública vivenciada nas favelas da cidade do Rio de Janeiro, este texto apresentará dados preliminares de uma pesquisa bibliográfica e de campo construída na confluência de duas temáticas: a do controle estatal dos territórios da pobreza e a maneira como estes territórios se organizam em relação aos poderes supralocais. Entendendo os poderes supralocais como estruturas que estão organizadas para além das localidades específicas e que confrontam estas localidades, tais como o sistema econômico e as organizações políticas, o judiciário e as burocracias administrativas estatais, conforme estabelecem Leeds e Leeds (1978).

Confrontados com a tarefa de estudar um fenômeno tão peculiar como são as favelas do Rio de Janeiro e sua atmosfera política, optamos pela utilização dos pressupostos apresentados pela Teoria das Representações Sociais tal como elaborada por Serge Moscovici (1961/1976) e segundo a abordagem processual desenvolvida por Denise Jodelet (2005).

Esta escolha metodológica deveu-se especialmente a poder permitir, diante da emergência deste novo fenômeno (as políticas de segurança do estado do Rio de Janeiro), que os sujeitos da pesquisa tivessem mais "liberdade" para suas exposições, e, também, principalmente porque a representação de violência nas favelas cariocas tem um alto grau de exposição midiática e é tema corrente nos discursos públicos dos atores políticos. Esta escolha foi feita para evitar que este estudo se reduzisse a um estudo de opinião, que Moscovici (1978) muito bem diferenciou dos estudos de representações sociais.

A pesquisa sobre a favela e a relação de seus moradores com a violência estatal, utilizando esta técnica das representações sociais, pode ser mais do que um instrumento para o "recolhimento de falas" dos moradores sobre seu cotidiano. Permite que os momentos de interação do pesquisador com os sujeitos da pesquisa, no encontro face a face, transformem o próprio ato de pesquisar em prolongamentos da esfera pública local, o que possibilita que os sujeitos tratem de maneira livre os temas definidos pelo objeto da pesquisa.

A teoria social clássica tem das representações sociais uma concepção abrangente a todos os seus ramos, as representações situam-se na conexão entre o pertencimento psicológico e social dos indivíduos. São categorias de pensamento que trazem em si as faculdades de expressar a realidade, questioná-la, justificá-la ou explicá-la, a partir da relação indivíduo/sociedade 
e do fluxo comunicativo que esta relação exige. Já no nascimento da sociologia, Durkheim aponta para a necessidade de se estudar de que forma as representações "se atraem ou se excluem, se fundem umas nas outras ou se distinguem", pois, segundo ele:

[...] o grupo não é constituído da mesma maneira que o individual, e as coisas que o afetam são de outra natureza. Representações que não exprimem nem os mesmos sujeitos, nem os mesmos objetos, não poderiam depender das mesmas causas. Para compreender a maneira como a sociedade representa a si mesma e o mundo que a cerca, é a natureza da sociedade, e não a dos particulares, que se deve considerar. (DURKHEIM, 2009, p. XXIII).

Diretamente associadas à teia de relações estabelecida entre os sujeitos, seus pares e o mundo as representações são, efetivamente, sociais e precisam ampliar as fronteiras da psicologia social como disciplina matriz. Elas se inserem no esforço teórico e acadêmico de estabelecer um diálogo entre as diversas formas de elaboração disponíveis ao cientista social. Como trilha teórica privilegiada, possibilitam um certo deslocamento de sentidos e reaproximam a psicologia social e a sociologia, duas disciplinas separadas pelo positivismo acadêmico, na medida em que propiciam a produção de um objeto analítico transdisciplinar, pois para se compreender uma representação social é necessário acionar elementos da cultura, da comunicação, da antropologia e da história, entre outros, do grupo pesquisado (CASTRO, 2005).

Definidas como ideias, ou categorias de pensamento que servem para expressar a realidade, em muitos momentos Ihe explicando, em outros lhe justificando, ou até mesmo Ihe questionando, as representações se apresentam como uma categoria que pode romper com as características impessoais que veem o conhecimento como racionalidade pura, pois estando efetivamente na base de todos os sistemas de saber, de uma maneira dialógica, são geradas pelas inter-relações e auxiliam na sua compreensão (MINAYO, 2012).

Tal dialogia viabiliza a percepção de como transcorre a relação sujeito-outro-objeto que, como parte da ação comunicativa, como uma estrutura mediadora, vincula o conhecimento do mundo ao redor à pessoa e à sua comunidade (JOVCHELOVITCH, 2011).

O dinamismo da vida social requer dos sujeitos uma constante tomada de posição frente ao cotidiano, é o preço que se paga por estar inserido em um grupo social. Trata-se de construir, consolidar e transmitir visões de mundo e, para dar cabo a esta tarefa, sujeitos e grupos sociais utilizam-se das representações.

Representar, nos recorda Jovchelovitch (2011), é propriamente o ato de dar forma, de tornar presente o que está ausente, o conceito de representação "está na base da inclusão e da exclusão - quem é e quem não é representado? - no centro do nosso conhecimento sobre nós mesmos e sobre o mundo em que vivemos" (JOVCHELOVITCH, 2011, p. 33).

As representações são, antes de tudo, um processo de disputa, um sistema que é construído no decurso da ação social dos sujeitos e seus grupos. "Elas implicam um trabalho simbólico que emerge das inter-relações Eu, Outro e objeto-mundo e, como tal, têm o poder de significar, de construir sentido, de criar realidade" (JOVCHELOVITCH, 2011, p. 35).

As representações sociais têm uma ação muito peculiar sobre os sujeitos, elas agem de maneira "prescritiva, isto é, elas se impõem sobre nós com uma força irresistível" (MOSCOVICI, 2011). Ou ainda, são:

Um sistema de valores, ideias e práticas, com uma dupla função: primeiro, estabelecer uma ordem que possibilitará às pessoas orientar-se em seu mundo material e social e controlá-lo; e, em segundo lugar, possibilitar que a comunicação seja possível entre os membros de uma comunidade, fornecendo-lhes o código para nomear e classificar, sem ambiguidade, os vários aspectos de seu mundo e da sua história individual e social. (MOSCOVICI, 1976: viii. apud DUVVEN, 2011, p. 21).

$\mathrm{Na}$ pesquisa qualitativa o social é visto como um mundo de significados passível de investigação e a linguagem dos atores sociais e suas práticas, como as matérias-primas dessa abordagem.

Muitos autores, não apenas de psicologia social, mas das ciências sociais de maneira geral, tem buscado relacionar conceitos como 
representação e construção da realidade, pensando em um homem (sujeito social) em busca de sentido para sua experiência de vida. Seguindo esta trilha, percebe-se que, ao falar de representações sociais, apesar de se ter os sujeitos sociais e seus atos como alvos da observação, não concentramos a análise no sujeito ontológico, possuidor de uma natureza comum, mas nos elementos determinados pelas construções particulares do campo social. "A questão central é o reconhecimento de que o olhar da Psicologia Social - e a análise das representações sociais - se dirigem ao social enquanto totalidade" (JOVCHELOVITCH, 2000, p. 79).

Serge Moscovici (2011) salienta que a finalidade de toda representação é tornar familiar o que não é familiar. Este ato de transformar o não-familiar em familiar é algo que se faz a todo o momento no intuito de dar forma as coisas. Portanto, as representações que os sujeitos fabricam vão sempre neste sentido de tornar comum algo que é incomum. Este processamento das relações se dá pela familiarização "onde os objetos, pessoas e acontecimentos são percebidos e compreendidos em relação a prévios encontros e paradigmas". (MOSCOVICI, 2011, p. 55).

Pondo isto em termos mais claros, o autor afirma que este movimento de familiarização está relacionado à segurança dos universos consensuais, pois, é ali que os sujeitos se protegem dos riscos, atritos ou conflitos que as relações sociais impõem.

Neste sentido, a mediação entre os indivíduos e o contexto social, estabelece a forma que as representações sociais adquirem no intento de trazer sentido material à produção simbólica de uma comunidade.

Esta tarefa de familiarizar o não-familiar é cotidiana e requer dos sujeitos um exercício cognitivo constante, através do qual acionam e, utilizam-se de dois instrumentos nomeados como ancoragem e objetivação.

O primeiro consiste em sintetizar significados diferentes e externos a fim de torná-los íntimos, ou seja, transformar um conceito que pode ser ameaçador ou indizível em uma imagem familiar.

Este é um processo que transforma algo estranho e perturbador, que nos intriga, em nosso sistema particular de categorias e o com- para com o paradigma de uma categoria que nós pensamos ser apropriada. [...] Ancorar é, pois, classificar e dar nome a alguma coisa. (MOSCOVICl, 2011, p. 61)

Ao fazer isto, o indivíduo passa a ocupar-se do segundo instrumento nomeado por Moscovici, assim, objetifica o desconhecido em uma realidade por ele já institucionalizada. Conforme explica Moscovici:

Objetificação une a ideia de não familiaridade com a realidade, torna-se a verdadeira essência da realidade. [...] Objetificar é descobrir a qualidade icônica de uma ideia, ou ser impreciso; é reproduzir um conceito em uma imagem. Comparar é já representar, encher o que está naturalmente vazio, com substancia. (MOSCOVICl, 2011, p. 71-72).

$\mathrm{Na}$ chamada abordagem processual das representações sociais - influenciadora da condução deste trabalho - inicialmente desenvolvida por Denise Jodelet (2005), em seu interessante estudo sobre as representações sociais da loucura em uma comunidade do interior da França, são desenvolvidas e apresentadas mais características das representações sociais.

Jodelet nos leva a entender o quanto as representações constituídas no âmbito da vida social se apresentam como categoria precípua na articulação que os sujeitos fazem a respeito de sua existência e inserção no grupo. Para a autora, elas são importantes como categoria de análise visto que, orientam os sujeitos no modo como nomeiam, definem e se posicionam em relação as mais diversas aparências da sua realidade cotidiana. (JODELET, 2001).

Jodelet defende que as representações, diante de seu caráter dinâmico e transversal, "estão ligadas tanto a sistemas de pensamento mais amplos, ideológicos ou culturais, [...], quanto à condição social e à esfera de experiência privada e afetiva dos indivíduos" (JODELET, 2001, p. 21).

Ocorre que as várias significações das representações expressas pelos indivíduos e seus grupos sociais atuam como referenciais que conduzem suas ações e interações na vida cotidiana.

Consequentemente, a partilha das definições abarcadas pelas representações solidifica, nos grupos, uma visão consensual da sua realidade. Esta visão partilhada pelos membros do 
grupo trata-se, de fato, da dinâmica social das representações. Ela serve de roteiro para posicionamento em relação a outros grupos (JODELET, 2001).

Retomando as elaborações de Moscovici (2011), em expressão já bastante conhecida, Denise Jodelet aponta que, as representações sociais seriam: "uma forma de conhecimento, socialmente elaborada e partilhada, com um objetivo prático, e que contribui para a construção da realidade comum a um conjunto social". (JODELET, 2001, p. 22). Dizendo isto, Jodelet especifica mais acerca das características das representações. Ela afirma que as representações, enquanto fenômenos cognitivos, abrangem o pertencimento social dos sujeitos em todas as suas variantes (práticas, modelos de conduta e pensamento), com todas as implicações afetivas e normativas que isso possa trazer (JODELET, 2001).

Percebemos, portanto, que a representação social está diretamente ligada às condutas individuais e coletivas, criando, ao mesmo tempo, categorias cognitivas e relações de sentido exigidas para a inscrição social de determinado grupo. Ela pode funcionar como predicado deste grupo, ou seja, "grupos sociais podem identificar-se, perceber-se, aliar-se ou rejeitar-se através dela" (HERZLICH, 1991, p. 25).

As representações inserem-se, assim, no limiar da percepção do sujeito enquanto agente que se posiciona no contexto social e grupal, a partir da memória recebida, fazendo com que o par sujeito-objeto esteja ligado por um saber efetivamente praticado.

Para identificar as representações sociais dos moradores do Morro do Andaraí acerca da Unidade de Polícia Pacificadora (UPP) local, optou-se por associar a observação do pesquisador em campo, com instrumentos de investigação de base qualitativa, através da prática de entrevista não diretiva. Para tal a solução encontrada foi distinguir-se da orientação mais habitual e seguir um caminho muito parecido com o utilizado por Machado (2008) e equipe na pesquisa "Vida sob cerco", onde investigam os efeitos da violência criminal e policial sobre os moradores das favelas do Rio de Janeiro. Sua opção foi a constituição do que chamaram de "coletivos de confiança", onde o recrutamento dos informantes pautava-se por critérios mais restritos como, por exemplo, a existência de uma relação prévia e direta destes com ao menos um dos pesquisadores da equipe, garantindo, assim, o fortalecimento da confiança mútua. Graças a este cuidado, os pesquisadores puderam tratar de um dos problemas mais comuns encontrados por quem estuda as favelas do Rio de Janeiro e seu cotidiano violento e minimizaram a sensação de perigo e possível exposição que os informantes sentem quanto às consequências do que dizem.

Assim sendo, para a pesquisa aqui relatada constituiu-se um "coletivo de confiança", a partir do qual foram realizadas as entrevistas. Este coletivo se originou de uma rede de relações prévias existentes entre um dos pesquisadores e três moradores, os quais indicaram os outros 11 participantes obedecendo-se os seguintes critérios: ser maior de 18 anos, ser morador do território do Morro do Andaraí há mais de 10 anos, estar desenvolvendo ou ter desenvolvido alguma atuação sócio-política no território.

É importante ressalvar que o perfil de respondentes foi elaborado sob a constatação de que as ações desenvolvidas por tais sujeitos na favela os credenciam junto aos demais moradores como "porta-vozes de sua comunidade" que, ao viver tanto tempo sob a coação de traficantes e policiais não sabe se podem ou se devem expor publicamente seus pensamentos.

As questões discutidas nas entrevistas originaram-se de um roteiro temático, definido a partir dos objetivos da pesquisa e que buscou abordar o cotidiano da vida na favela em quatro momentos distintos: (1) a relação da comunidade com a polícia e com os traficantes antes da chegada da ocupação militar; (2) a chegada dos policiais para a ocupação e o posicionamento da comunidade em relação a isto; (3) o relacionamento entre comunidade e polícia no momento atual, buscando identificar relatos de experiências violentas ou de controle da vida social; (4) perspectivas futuras em relação a esta ação estatal de ocupação do território.

\section{Favela - História e Representações}

As construções sociais a respeito das favelas do Rio de Janeiro, historicamente, apresentam estes territórios como lócus da pobreza e delinquência, local de esconderijo de traficantes e residência de desocupados, espaço que assusta as classes mais abastadas e estimula 
o poder público a agir, via de regra, com força e violência contra seus moradores (VALLA, 1986; VALLADARES, 2000, 2011; GONÇALVES, 2013). O pensamento urbanista dos primeiros anos do século XX absorveu uma concepção organizativa de cidade pautada pelos interesses do crescente mercado imobiliário, cuja orientação era regular a divisão espacial da cidade, segundo suas necessidades de acumulação de capital.

A principal reforma vivida pela cidade, posta em prática pelo prefeito Pereira Passos, significou o "aburguesamento" da cidade o que exigiu do Estado e suas instituições mais iniciativas de controle sobre os não detentores da cidadania formal, notadamente, os negros, pobres e moradores das nascentes favelas. Às estratégias de urbanização e modernização da cidade somaram-se propostas de redefinição da ação policial e do controle operado por esta instituição nos territórios pobres que moldam, até hoje, os parâmetros de comportamento e sociabilidade na relação existente entre a cidade e suas favelas (NEDER, 1997).

Tal situação ocorreu porque havia da parte do poder público uma intensa necessidade de entender tal reordenação dos pobres no espaço urbano e "na origem desse conhecimento impunha-se uma finalidade prática: conhecer para denunciar e intervir, conhecer para propor soluções, para melhor administrar e gerir a pobreza e seus personagens" (VALLADARES, 2000, p. 7).

Nesta mesma época dá-se a valorização financeira de muitos terrenos ocupados por favelas nas zonas sul e central da cidade. É deste período a proibição do Código de Obras $^{2}$ do Rio de Janeiro de se construir novas moradias nas favelas (VALLADARES, 2011; GONÇALVES, 2013).

Durante todo o século $X X$, os locais de moradia dos mais pobres, primeiro os cortiços e depois as favelas, foram alvos de discursos e

\footnotetext{
2 O Decreto Municipal do Rio de Janeiro $\mathrm{n}^{\circ} .6 .000$, de $1^{\circ}$ de julho de 1937, estabeleceu, pela primeira vez, em seu artigo 349 , um conceito jurídico oficial para tipificar as favelas, além de tratar das demais questões relacionadas à postura urbana como construções, loteamentos, altura dos prédios e zoneamento. Suas especificações vigoraram até 1970 e influenciaram toda a expansão urbana do Rio de Janeiro e de outros municípios que o tomaram como exemplo.
}

legislações higienistas que, entendendo estes locais como a moradia de grupos socialmente perigosos, apontavam que a condição social de tais sujeitos causava e reforçava os fatores naturais de contaminação e violência (GONÇALVES, 2013).

Em complementação à legislação do Código de Obras segue-se um período de criação de conjuntos habitacionais e remoção dos moradores das favelas das Zonas Sul e Norte (com alto valor fundiário) para estes conjuntos, em regiões afastadas do grande centro. Esta política se intensifica, após o golpe civil-militar de 1964, quando setores que defendiam claramente as remoções passam a ocupar espaços de maior influência na formulação de políticas públicas (BURGOS, 2006).

Já na década de 1970, a crise do capital enfrentada pelos Estados e a consequente emergência de governos neoliberais, especialmente, em países da América Latina, trouxe uma nova maneira de enfrentar o problema da habitação e da favelização das grandes cidades, influenciada pelas cartilhas do Fundo Monetário Internacional (FMI) e do Banco Mundial. Sobre esta nova conjuntura, Davis vai dizer que:

Melhorar as favelas em vez de substituí-las tornou-se a meta menos ambiciosa da intervenção pública e privada. Em vez da reforma estrutural da pobreza urbana imposta de cima para baixo, [...] a nova sabedoria do final da década de 1970 e início da de 1980 exigia que o Estado se aliasse a doadores internacionais e, depois, a ONGs para tornar-se um "capacitador" dos pobres. Em sua primeira interação, a nova filosofia do Banco Mundial (...) insistia numa abordagem de oferta de "lotes urbanizados" (fornecimento de infraestrutura básica de água e esgoto e obras de engenharia civil) a fim de ajudar a racionalizar e melhorar as habitações construídas pelos próprios moradores. (DAVIS, 2006, p. 79-80).

No Rio de Janeiro, a percepção desta nova maneira estatal de agir nas favelas fica evidente na substituição das remoções pelo oferecimento de obras de infraestrutura e de diversos programas das três esferas governamentais. Esta mudança de orientação governamental atrelada a mudanças na legislação em relação às favelas, à construção de habitações de alvenaria e à chegada de concessionárias de serviços públicos, 
desde o final dos anos 70 , constituem, para alguns autores da sociologia urbana, dispositivos capazes de tornar as favelas bairros das cidades.

Contudo, em contraposição à tese da "vitória da favela", como é apresentada por Zaluar e Alvito, na introdução de sua coletânea "Um Século de Favela": "Após 100 anos de luta, empregando diferentes formas de organização e de demanda política, inclusive o carnaval, a favela venceu." (ZALUAR e ALVITO, 2006, p. 21). O que se percebe é que tais ações de "pacificação" têm produzido mais discursos céticos sobre o futuro do que falas otimistas.

Efetivamente, se a favela venceu, como defende a tese, os favelados não venceram, visto que, nos dias atuais, permanecem travando um intenso combate em busca de reconhecimento e respeito aos seus direitos mais fundamentais. Há na atualidade, como recorda Machado da Silva, uma "continuidade do problema da favela" nas cidades brasileiras. A desarmonia, bem lembra o autor, reside no fato de os moradores das favelas permanecerem no lugar que lhes foi estabelecido na hierarquia social, o de sujeitos obrigados a reproduzir as desigualdades constituintes da sociedade brasileira (MACHADO DA SILVA, 2002).

Por suas especificidades de localização geográfica, e pela conjugação de um amplo processo de segregação econômico, jurídico-político e simbólico gerador de uma ausência, quase que total, de serviços públicos e uma presença fragilizada do Estado, as favelas do Rio de Janeiro se transformaram, a partir da década de 1980, no ambiente propício para o comércio e distribuição de toneladas de drogas no varejo.

Com isso, seu controle territorial passou a ser, para os grupos criminosos que exploram este comércio, uma necessidade ao bom andamento da empresa criminal. Consequentemente, os combates extremamente violentos entre as diversas quadrilhas pelo controle territorial, a fim de expandir seus negócios, se intensificaram na década de 90.

Adicionadas a este ambiente conflagrado, as ações reativas contra essas quadrilhas passaram a ser rotina, com o Estado agindo de maneira repressiva dentro das favelas contra o mal representado na figura do traficante favelado. No meio deste tiroteio, os moradores das favelas criminalizados desde sempre.
Conforme sustenta Leeds (2006, p. 235):

[...] a violência física e criminosa resultante do tráfico de drogas é uma forma visível e palpável da violência empregada pelo Estado, e ela mascara uma violência estrutural-institucional mais oculta, ao mesmo tempo em que perpetua relações políticas neoclientelistas com essas comunidades de baixa renda.

Somado a isto, as interpretações que a ordem estatal aciona em relação às favelas são, desde a origem destes territórios na paisagem das cidades brasileira, e até os dias atuais, o cimento que dá liga à ideia de partição, a fronteira não demarcada, mas conhecida por todos entre o "morro e o asfalto" (DA SILVA, 2005).

Efetivamente, expor-se na cidade com a distinção social de ser da favela, significa a seus moradores carregar uma marca que lega a estes sujeitos toda sorte de infortúnios, significa "uma experiência de discriminação e de luta identificatória que retira da sua população o direito a uma auto-interpretação positiva" (JOVCHELOVITCH e PRIEGO-HERNÁNDEZ, 2013, p. 41). Tal "estigma" é facilmente percebido no tratamento policial dado aos territórios favelados, o qual dissipa as distinções entre as pessoas que ali residem, principalmente entre os moradores que não têm envolvimento com a criminalidade do tráfico de drogas e os poucos que atuam neste ramo.

Os estereótipos que apresentam a favela como local da pobreza e delinquência desde seu surgimento estão ainda hoje muito presentes, seja nas discussões do senso comum propagadas pela grande mídia, seja no universo reificado da pesquisa acadêmica.

O atual alarde da "crise urbana" que vivemos nas grandes cidades brasileiras, em especial no Rio de Janeiro, decorrente de um confuso e contínuo processo que envolve padrões reativos de ação estatal, uma descomunal rede de quadrilhas criminosas, corrupção policial e toda sorte de crimes associados à economia da droga, faz ver a violência urbana e suas consequências como um problema encarcerado em si mesmo (MISSE, 1999).

A atuação do Estado nestes territórios é constantemente influenciada pela lógica do confronto militar, priorizando as Políticas de Segurança como caminho para o controle e solução dos mais variados problemas neles 
encontrados. Acontecendo, na maioria das vezes, o que Jorge Da Silva nomeou como: "militarização ideológica da segurança pública, com a incorporação de conceitos como ocupação, vitória, inimigo, cerco, teatro de operações". (DA SILVA, 2014, p. 357).

$\mathrm{Na}$ atualidade, apesar de iniciativas interessantes para a melhoria das condições de vida dos moradores das favelas, a forma do poder público e da sociedade se relacionar com estes territórios permanece inalterada. A atmosfera política e social que a favela experimenta leva o conjunto da cidade do Rio de Janeiro a vê-la como um lugar perigoso, necessitado de uma ação colonizadora por parte do poder público.

Os juízos que apresentam a favela como local da pobreza e delinquência, desde seu surgimento, são produto de uma contínua acumulação social da violência no Rio de Janeiro e, ainda hoje, estão muito presentes. A violência estrutural sofrida pelas classes pobres, que são obrigadas a mediar, a todo momento, sua integração no espaço público com os comandos criminosos de um lado e a polícia de outro, não é algo episódico ou acidental. Entalhada na estrutura da sociedade ela está ligada diretamente à negação dos direitos mais básicos aos cidadãos.

Como uma gramática das relações sociais, propriamente, um sistema de regras que condiciona as interações entre os indivíduos, esta "sociabilidade violenta", fez com que as relações sociais no interior dos territórios da pobreza se estabelecessem com base em padrões de medo e desconfiança recíprocos (MACHADO DA SILVA, 2004).

É assim que, durante os últimos 30 anos, a exposição pública das violências, tanto estatal como da praticada pela empresa criminal, tornou cada vez mais as favelas fronteiras simbólicas dentro das quais se supõe que toda dimensão social seja organizada pelo ilícito. Suposição que "autoriza" o Estado a agir de modo a reordenar estes territórios, segundo padrões formais.

Tentando romper com a tradição de deixar o território de diversas favelas cariocas sob o comando total do comércio de drogas, o governo do Estado do Rio de Janeiro inovou promovendo uma ocupação permanente do espaço, sufocando este comércio, antes ostensivo, e criando a ideia de presença da ordem pública, retomando o território e "reintegrando-o" à cidade e chamou esta iniciativa de Unidades de Polícia Pacificadora (UPPs).

Aentrada em campo desta nova maneira de ação policial estatal, além de gerar expectativas em toda a sociedade fluminense e brasileira, interpela a esfera pública local das favelas, causa tensões desta com o ente estatal e exige dos moradores a readequação de seu instrumental interpretativo da realidade e a tomada de determinadas posições.

Evidentemente, a presença policial constante no interior das favelas age como um poder moderador de modo a estabelecer códigos de conduta que antes não eram acionados ou praticados cotidianamente pelos moradores.

Em que pese a diminuição dos índices oficias de mortes nas favelas ocupadas e um desaparecimento visível do poderio militar do tráfico de drogas, até que ponto a presença coercitiva da força policial se contrapõe à consolidação da esfera pública local e a uma real integração dos moradores à cidade institucional?

Como concluiu Fleury (2012) sobre a primeira UPP instalada, a do Morro Santa Marta, há ainda uma deficiente proteção aos direitos de cidadania e a população local permanece afligida pela insegurança, dado que o aparato com o qual o Estado tem chegado a este território e podemos dizer que a todas as 38 favelas com UPP é:

[...] basicamente o aparato coercitivo, não havendo o mesmo empenho na construção institucional dos direitos de cidadania. A desproporcionalidade entre o contingente de 126 policiais e os 27 membros da equipe de saúde da família, com uma disparidade enorme de recurso, demonstra esse argumento. (FLEURY, 2012, p. 219).

É inquestionável que, no decurso da vida social, os sujeitos assimilam o "novo" que se lhes apresenta nos ambientes em que estão inseridos e, ato contínuo, compartilham estes objetos, estabelecendo, desta maneira, o que conhecemos como senso comum. É no intenso jogo de trocas, efetivamente, na manifestação concreta do que é viver em sociedade, que se estabelecem os momentos de encontro e conversação geradores do senso comum como categoria interpretativa da realidade.

Como Douglas (2014) vai lembrar, de fato, a ideia de sociedade [o estar na esfera pública 
com todas as implicações, limites externos e estrutura interna] é iconicamente poderosa, pois atua no sentido de controlar ou estimular os sujeitos à ação.

$\mathrm{Na}$ questão que se discute aqui - a da chegada das UPPs nas favelas cariocas e as representações sociais acionadas a partir daí - acredita-se que estas propõem às favelas e seus moradores uma nova realidade, que pode ser compreendida desde as perspectivas instrumentais das representações como saberes do senso comum que, por sua vez, constituem-se como um integrado de mensagens e símbolos que ocorrem no compartilhamento entre os sujeitos.

Sobre esta dinâmica, Bourdieu (2011) indica que as concepções da realidade são estabelecidas pelas relações entre os indivíduos, ou o habitus - um conjunto de categorias culturais adquiridas no jogo social e que predeterminam as escolhas. Como um apanhado cognitivo, o habitus, segundo Bourdieu, ao sofrer tensões das conjunturas do ambiente onde os indivíduos estão inseridos, exerce influência direta na apropriação do cenário e na ação que põem em prática, mediante suas conveniências simbólicas ou materiais.

Compreende-se, portanto que o habitus, tal como definiu Bourdieu, atua nas classificações mais utilitárias, as quais "estão sempre subordinadas a funções práticas e orientadas para a produção de efeitos sociais" (BOURDIEU, 2011, p. 112). Neste sentido, sua função é familiarizar os indivíduos às novas situações colocadas no ambiente em que vivem.

A concepção de habitus de Bourdieu dialoga diretamente com as observações de Wagner (2000) para o processo de constituição da representação social que seria ao mesmo tempo:

[...] conteúdo mental estruturado - isto é, cognitivo, avaliativo, afetivo e simbólico - sobre um fenômeno social relevante, que toma a forma de imagens ou metáforas, e que é conscientemente compartilhado com outros membros do grupo social" além de "... um processo público de criação, elaboração, difusão e mudança do conhecimento compartilhado. (WAGNER, 2000, p. 3-4).

Funcionando como um sistema de interpretação da realidade, as representações sociais dos moradores de favelas com UPPs instaladas, em relação a esta política, embora não determinem completamente suas tomadas de decisões, por serem originadas no desenrolar das comunicações interpessoais da vida cotidiana, orientam seu universo de possibilidades.

Assim, na medida em que esta ação política de segurança atua na esfera pública como algo singular, perscrutar as representações dos moradores a seu respeito e entender a estruturação do pensamento do senso comum local sobre tal empreitada governamental, apresenta-se como tarefa fundamental.

A conjuntura pós-UPP assedia as práticas correntes dos sujeitos e gera toda uma atividade narrativa nos espaços comuns. E é nos espaços comuns que se formulam e são partilhadas as opiniões a respeito do objeto. O compartilhamento das ideias do senso comum lembra Castro é, portanto, "a chave paradigmática das representações sociais" (CASTRO, 2015, p. 2).

Vistas como uma "atmosfera" que se estabelece em relação aos indivíduos e aos grupos, para se efetivarem, as representações pressupõem que haja um "território comum", mesmo com toda a dificuldade contemporânea de se delimitar parâmetros identitários (CASTRO, 2015). É neste "território comum" de compartilhamento de ideias que se dá a ancoragem. O trabalho da ancoragem consiste no ato de transformar o objeto "novo" e por isso perturbador, através de um sistema particular de categorização.

O exemplo dado por Moscovici (2011) a respeito do estudo de Jodelet sobre os doentes mentais no interior da França fornece pistas para, em comparação, entender como possivelmente vem se dando a ancoragem do novo objeto UPP na realidade dos moradores de favelas. Os doentes mentais do estudo de Jodelet, lembra Moscovici, colocados em convívio com a comunidade de Ainay-le-Chateau passaram a ser julgados por padrões convencionais que os moradores da cidade tinham para o desviante. Neste movimento de categorizar o novo objeto (os doentes mentais) e as ideias a respeito dele aos paradigmas que já possuíam, os moradores da cidade francesa o ancoraram em seu universo de explicações familiares. Dito de outra maneira, este ato de "categorizar alguém ou alguma coisa, [significou aos moradores da cidade francesa] escolher um dos paradigmas [estocados em sua memória] de modo a estabelecer uma relação 
positiva ou negativa com ele". (MOSCOVICI, 2011, p. 63).

A chegada das UPPs seria, então, o não-familiar que se apresenta às vistas dos moradores de favelas. Este não-familiar da presença constante dos policiais no território é posto em confrontação com as categorias familiares que já faziam parte do pensamento coletivo, onde ações policiais seguem um enredo muito bem determinado de incursão violenta a estes territórios.

\section{A "pacificação"}

A rotina das favelas do Rio de Janeiro, já muito movimentada pelo ambiente gerado com as disputas territoriais entre os comandos criminosos e entre estes a polícia, passou, a partir de novembro de 2008, a contar com mais um episódio emblemático de como se processam as ações estatais para com os territórios da pobreza. A referência é ao que ficou conhecido como o maior programa desenvolvido pelo Governo do Estado do Rio de Janeiro, no sentido de "pacificar" as favelas controladas por traficantes de drogas e seu poderio militar.

Tudo começou com a ocupação do Morro Santa Marta por 130 policiais, no dia 19 de novembro de 2008. A chegada destes homens ao território seria apenas mais uma incursão da polícia, no intento de capturar traficantes sem muita importância para quem não mora na favela. Contudo, iniciava-se uma sessão do que se tornou o roteiro atual da política de segurança do governo do Estado para com os territórios ditos conflagrados.

No primeiro momento, como podemos comprovar com as notícias dos jornais de grande circulação, nem o próprio governo do Estado sabia ao certo qual era o objetivo daquele ato, chegando a dizer que o objetivo seria promover um "choque de ordem", pois com a presença da polícia de maneira ostensiva, as diversas concessionárias de serviços públicos (luz, água, gás, etc.), poderiam entrar no território e atuar livremente.

As discussões que se seguiram à chegada da polícia no morro Santa Marta foram delineando aquela nova forma de agir do governo, começou-se a falar na instalação de "um novo modelo de policiamento" "com ações de duração infinita", "um laboratório, um modelo de política de segurança pública" ${ }^{3}$ e que este modelo seria estendido para outros territórios controlados pelos traficantes. Alguns dias após a ocupação, os jornais noticiavam que a presença da polícia havia feito cessar a venda de drogas nas bocas de fumo e, exatamente um mês após a chegada dos policiais no Santa Marta, o governador do Estado subiu o morro para inaugurar um Posto de Policiamento Comunitário.

Desde então, por muitos meses, as ocupações policiais se seguiram e os postos de policiamento mudaram de nome, são denominadas de Unidades de Polícia Pacificadora (UPP) e estão presentes em 38 favelas da cidade.

Desde a primeira incursão e ocupação permanente, em finais de 2008 até a atualidade, a Secretaria de Segurança tem tentado elaborar muito a respeito de seu programa de "pacificação". Segundo o governo, novos policiais estão sendo formados dentro das concepções de "policiamento comunitário" e de "proximidade", elaboradas pela atual cúpula da segurança do estado.

Até hoje a pouca fundamentação legal do Programa (três Decretos-lei) ${ }^{4}$ pode ser considerada como um marcador importante de como, mais uma vez, nas políticas de segurança executadas no Rio de Janeiro se "coloca o carro na frente dos bois".

Tomando como base os documentos oficiais que tratam da "pacificação" Cano, Borges e Ribeiro (2014) analisam que, desde seu surgimento, "(...) o projeto das UPPs avançou de forma experimental e pragmática, sem responder a um plano previamente desenhado" (CANO, BORGES e RIBEIRO, 2014, p. 18).

Os autores constatam que somente dois anos após a edição dos dois primeiros decretos que criam as UPPs ${ }^{5}$ há um avanço dos pontos de

\footnotetext{
${ }^{3}$ Declarações do secretário de segurança José Mariano Beltrame veiculadas em matérias do jornal Extra, de 02 de dezembro de 2008: "Dona Marta livre dos bandidos" http://extra.globo.com/noticias/rio/dona-marta-livre-dos-bandidos-619813.html.

${ }^{4} \mathrm{O}$ fato de ter sido criado por decreto aponta para a baixa institucionalidade da ação. Junto a isto, uma tentativa de discussão dos critérios para a implantação das UPPs, apresentada pelo então deputado estadual Alessandro Molon (PT), o projeto de lei no $2.966 / 2010$, foi majoritariamente vetado pelos representantes da bancada do governo na Assembleia Legislativa.

${ }^{5}$ O Decreto-lei $n^{\circ} .41 .650$, de 21 de janeiro de 2009 cria as Uni-
} 
vista da estrutura, dos objetivos e da organização de atuação do Programa. Com o Decreto-lei 42.787, de 6 de janeiro de 2011, há o estabelecimento de que as UPPs "destinam-se a aplicar a filosofia de proximidade nas áreas designadas para a atuação" (Art. $1^{\circ}$ ), adiante, no $\S 1^{\circ}$ deste artigo há a apresentação dos critérios para a escolha das comunidades onde se deve implantar UPPs: "comunidades pobres, com baixa institucionalidade e alto grau de informalidade, em que a instalação oportunista de grupos criminosos ostensivamente armados afronta o Estado Democrático de Direito".

$\mathrm{O}$ artigo $2^{\circ}$ estabelece que o "programa de pacificação" deve ser realizado em quatro etapas interligadas:

I. Intervenção Tática - onde há principalmente o emprego do Batalhão de Operações Especiais (BOPE), do Batalhão de Polícia de Choque (BpChoque), duas das unidades policiais mais impregnadas pela lógica do confronto militar, para a recuperação do controle estatal;

II. Estabilização - ocasião em que as ações de intervenção tática e cerco da comunidade são intercaladas;

III. Implantação da UPP - quando há efetivamente a chegada dos policiais "especialmente capacitados para o exercício da polícia de proximidade" (sic);

IV. Avaliação e Monitoramento - quando, após instalada a UPP, há a produção de dados sobre sua presença na comunidade.

A redação dos demais artigos do decreto delineia questões administrativas do cotidiano das UPPs, classificando-as segundo seu contingente e estabelecendo critérios para a escolha dos comandantes, entre outras questões, mas, dentre estes, o que chama atenção é o artigo $10^{\circ}$ que ordena no inciso I de seu parágrafo único que o Instituto de Segurança Pública (ISP) - autarquia estadual responsável por produzir estudos e análises das incidências criminais - no prazo de (60) dias a partir da publicação do Decreto deveria produzir e divulgar o "Programa de Polícia

dades de Polícia Pacificadora na estrutura da Polícia Militar e o Decreto-lei $n^{\circ} .41 .653$ de 22 de janeiro de 2009 institui o pagamento de uma gratificação salarial para os policiais que delas fizerem parte.
Pacificadora", onde deveriam "constar, dentre outros tópicos: seus objetivos, conceitos, estratégias, indicadores e metodologia de avaliação".

Até o momento de finalização da redação deste texto foram visitadas todas as páginas oficiais dos órgãos do Estado, bem como foi feita uma minuciosa pesquisa sobre publicações que tratassem da questão na rede mundial de computadores, mas não foi possível encontrar qualquer menção a este documento.

Nos tempos atuais, a presença ostensiva dos comandos criminosos realmente não é mais vista nas favelas ocupadas e o tráfico reduziu-se a vendas eventuais conhecidas como "esticas". No entanto, a grande mídia tem noticiado uma série de ataques às sedes das UPPs e constantes confrontos entre traficantes e policiais destas unidades, o que demonstraria uma tentativa dos criminosos de restabelecer suas bases de controle.

Outro percalço a ser enfrentado pela nova política de segurança que vem sendo verificado, e que será discutido adiante, é o risco de policiais das UPPs ocuparem certo papel de mediação dos conflitos internos das comunidades e até mesmo agirem de forma a tutelar a sociabilidade em seu interior. Mormente, o que se vê após a chegada dos policiais militares é uma série de reclamações dos moradores a respeito da truculência utilizada como instrumento de controle do seu cotidiano.

Como em uma continuação da "metáfora da guerra" as principais críticas dos moradores apontam para a deficiência na oferta de serviços sociais e para certa policialização da ação política das organizações de base nas favelas, principalmente, das associações de moradores, como foi comprovado por Leite (2014), para quem:

[...] os agenciamentos e dispositivos acionados nas favelas, no campo da "pacificação", constituem uma inflexão nos modos de gestão da vida e de administração de conflitos nessas localidades que, embora incida em alguns aspectos da política de segurança pública praticada nesses territórios desde a década de 1980, não rompe completamente com a noção de "guerra" mobilizada por esta, e sim desloca seu campo de atuação. (LEITE, 2014, p. 625).

Se no passado a ação do Estado se pautou por uma orientação de controle e até mesmo 
tentativa de extinção das favelas do ambiente urbano da cidade do Rio de Janeiro com ações que foram desde uma política sanitarista, a remoções com criação de parques proletários e perseguição as lideranças comunitárias, nos tempos atuais, as ordens ideológica, política e econômica que compõem o Estado continuam a olhar para as favelas como o espaço onde identificam a desordem e a causa dos problemas sociais enfrentados pelo conjunto da cidade. Espaço que por isso precisa ser reordenado - pacificado para acabar com ideia da partição - e o principal instrumento utilizado para isso continua sendo a polícia e seus fuzis.

Para com os territórios da pobreza a solução é a guerra, como pode ser comprovado nas palavras do secretário de Segurança José Mariano Beltrame: "Não é que a cidade esteja em guerra, mas você possui núcleos que têm que ser tratados dessa forma"6.

Como uma reedição do mesmo roteiro, as ocupações militares das favelas do Rio de Janeiro por meio das UPPs, têm sido alvo de seguidas denúncias de violações dos diretos humanos, com casos de assassinatos, estupros e torturas.

Jorge da Silva, um dos estudiosos que há muito vem se debruçando sobre este tema aponta que:

Um dos principais entraves a uma abordagem mais consequente é que a violência urbana tem sido encarada como um problema em si mesmo, independentemente dos fatores sócio-histórico-econômico-culturais que a retroalimentam. No calor das paixões, as propostas de solução, não raro, partem do suposto - absolutamente falso - de que é possível "acabar com a violência". No caso das drogas, por exemplo, "acabar com os traficantes" (e não com o tráfico); ou mandá-los para bem longe, como se fosse possível, mantido o modelo de "guerra as drogas" no mundo, quebrar a corrente entre tráfico e uso. (DA SILVA, 2012, p. 395)

O ponto levantado pelo autor, e que pode produzir muita concordância entre diferentes interlocutores, é o entendimento de que lutar

\footnotetext{
${ }^{6}$ Entrevista concedida ao site "Operacional - Defesa e Segurança", disponível em: http://www.revistaoperacional.com.br/ entrevistas/entrevista-jose-mariano-beltrame/ Acessado em $11 / 02 / 2015$ as $00 \mathrm{~h}$ e $47 \mathrm{~min}$.
}

contra a violência que assola nossas cidades - que tem no tráfico de drogas e seus conflitos sua principal causa-, não é uma ação apenas de polícia, mas deve envolver uma ação pública que pressuponha a interlocução entre o poder estatal e a sociedade civil.

\section{Campo}

De agora em diante nos encarregaremos de descrever as representações sociais mobilizadas pelos moradores do Morro do Andaraí em relação à chegada e ocupação de seu território pelas forças policiais. A descrição destas representações sociais, acreditamos, permitirá perceber a dinâmica de um processo histórico de incorporação de práticas sociais em relação à favela.

Surgido em fins do século XIX, mesma época em que se iniciam as ocupações de favelas mais conhecidas da cidade, como os Morros da Providência e de Santa Marta, atualmente, o Morro do Andaraí se conjuga com mais cinco comunidades (Jamelão, Arrelia, Parque João Paulo II, Nova Divinéia e Borda do Mato), formando o chamado "complexo" do Andaraí, com uma área territorial de $449.804 \mathrm{~m}^{2}$ e com uma população estimada de 9.704 habitantes, segundo dados do Instituto Pereira Passos, com base no Censo 2010 do IBGE, conforme pode ser visto na tabela abaixo:

Tabela 1: Comunidades que compõem o Complexo do Andaraí

\begin{tabular}{|l|c|c|}
\hline \multicolumn{1}{|c|}{ Comunidades } & População & Domicílios \\
\hline Jamelão & 943 & 262 \\
\hline Morro do Andaraí & 1.760 & 557 \\
\hline Arrelia & 1.972 & 606 \\
\hline Pq. João Paulo II & 2.615 & 810 \\
\hline Nova Divinéia & 1.975 & 627 \\
\hline Borda do Mato & 420 & 131 \\
\hline Total & $\mathbf{9 . 6 8 5}$ & $\mathbf{2 . 9 9 3}$ \\
\hline
\end{tabular}

Fonte: Instituto Pereira Passos, com base em IBGE, Censo Demográfico (2010). Adaptado.

A UPP do Andaraí foi implantada em 28 de julho de 2010 e sua sede está localizada na Rua Santo Estevão, entrada principal da favela. Ela conta, atualmente, com um efetivo de 219 policiais. 
Figura 1 - Área de abrangência da UPP Andaraí

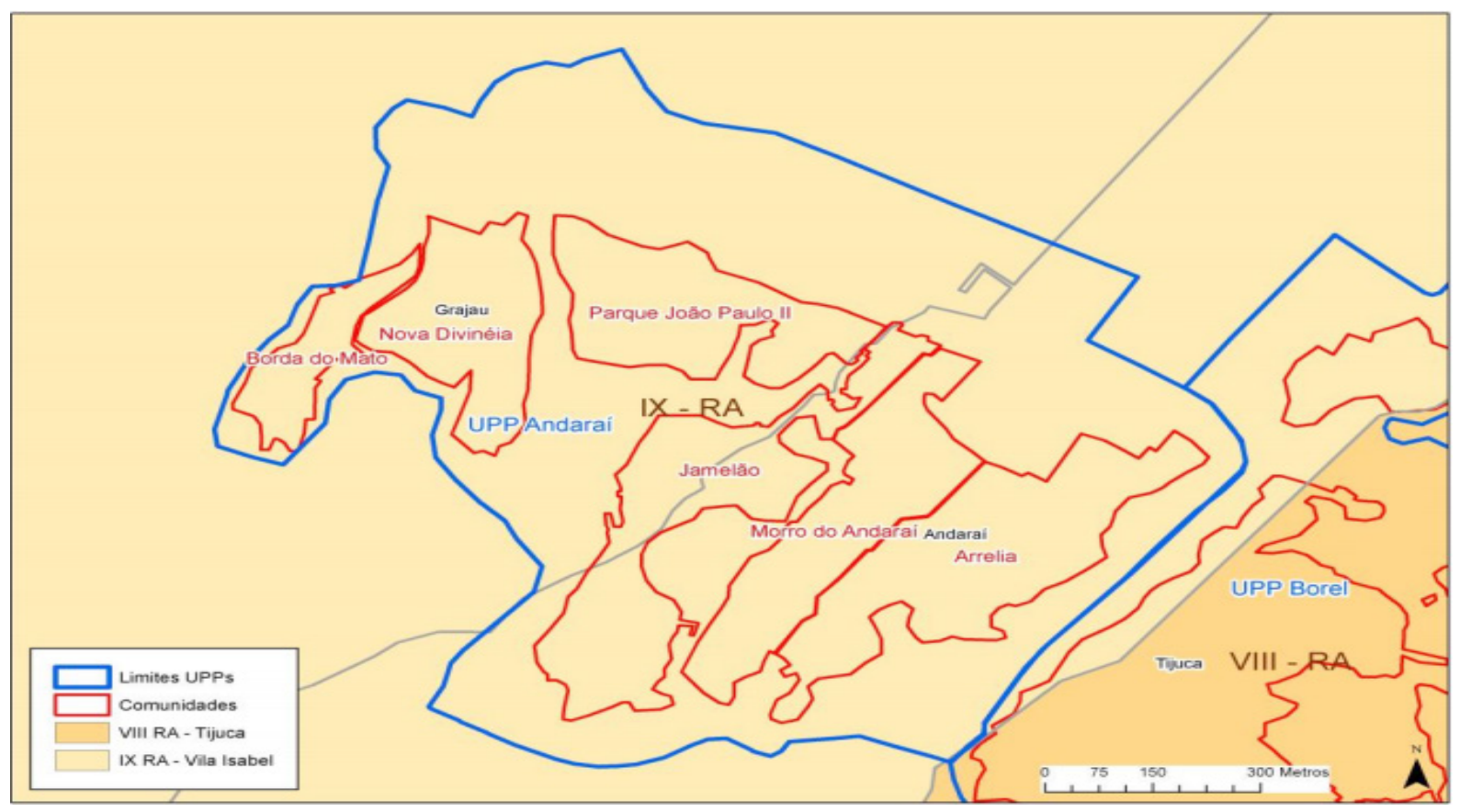

Fonte: SABREN/IPP 2011. Adaptado.

A partir das primeiras falas dos moradores colhidas nas entrevistas de campo, percebe-se que no Andaraí, diante do cotidiano violento experimentado pela presença de traficantes, havia uma grande expectativa pela chega da polícia para ocupação permanente do território. Conforme foi relatado pelos entrevistados:

Morador: "Os moradores já queriam [a UPP]. Nós estávamos na verdade imaginando quando seria esse momento que era de redenção da favela, porque pô, estava toda entregue ao tráfico.

Toda hora tinha a presença do $\mathrm{BOPE}^{7}$ e ninguém quer ninguém de preto encapuzado entrando na sua casa, ou andando perto dos teus filhos, da sua mulher, pô da sua mãe..." (Morador 1, 27 anos)

Esta sensação de "redenção" logo da chegada das UPPs não é exclusividade do Morro

\footnotetext{
${ }^{7}$ O Batalhão de Operações Policiais Especiais (BOPE) é facilmente reconhecido por seu uniforme preto e pelo brasão contendo uma caveira transpassada por uma faca e duas pistolas cruzadas atrás de si - é uma tropa de elite da Polícia Militar do Rio de Janeiro, treinada na lógica do combate de guerrilha urbana. Conforme estabelecido pelo Decreto $n^{\circ} 42.787$, de 06 de janeiro de 2011, o BOPE é empregado em duas das quatro fases previstas para a implantação de uma UPP, a "intervenção tática" e a "estabilização".
}

do Andaraí. Desde as primeiras ocupações de favelas, os relatos de expulsão de traficantes apontavam para uma possível "devolução" destes territórios a seus moradores, o que, supostamente, atuou diretamente na percepção de segurança do conjunto da cidade.

Com efeito, os dados oficiais divulgados pelo ISP, Instituto de Segurança Pública ${ }^{8}$, apontam para uma redução em números absolutos dos casos de crimes violentos no Morro do Andaraí, principalmente, nos homicídios dolosos, passando de 04 ocorrências em 2010, ano de implantação da UPP para 1 ocorrência em 2014. Os mesmos dados indicam que, em 2010, houve 04 mortes decorrentes de autos de resistência e nenhuma em 2014.

O auto de resistência (autorizado pelo Decreto-Lei 3.689/41 - Código de Processo Penal) consente no uso de quaisquer meios necessários para que o policial se defenda ou vença a resistência, mesmo que isso implique grave lesão ou a morte do possível criminoso. E para atestar a veracidade das informações, determina-se que apenas seja feito um auto, assinado por duas testemunhas. Este dado específico em relação aos autos de resistência denota a diminuição

${ }^{8}$ Disponível em: http://www.isp.rj.gov.br/Conteudo.asp?ident=61 
na letalidade da ação policial, já que esta ainda é uma explicação usual para os mortos em decorrência de conflitos com a polícia, no Morro do Andaraí, após a implantação da UPP local.

Como relatam os moradores, a sensação de segurança experimentada na comunidade com a ausência visível dos traficantes, a diminuição dos acontecimentos violentos e a chegada de concessionárias de serviços, antes impedidas de atuar livremente, os fez entender que haveria uma possível integração com a cidade oficial.

Ao que parece, esta sensação gerou um consenso provisório sobre as UPPs e fez crer que sua atuação se estenderia não apenas aos males identificados pela presença acintosa de traficantes armados nas favelas e seu comércio, mas que sua força cintilaria sobre toda ordem de crimes influenciados por esta modalidade de crime. A admiração pela UPP estimulou a sensação da inauguração de uma "nova cidade", onde se viveria sem medo (FRIDMAN, 2014).

Contudo, este consenso acaba sendo mais uma utopia ancorada no controle policial, que intimida as ações violentas por meio do controle contínuo. O qual, em alguns momentos, até serve de contendor da violência exacerbada, mas que talvez conserve em si todos os atributos já conhecidos da "antiga cidade". "Não há qualquer aceno à vida melhor, à vida desejada", presente em qualquer utopia. É "uma utopia que conserva todas as circunstâncias geradoras do medo" (FRIDMAN, 2014, p. 613).

O que foi percebido no trabalho de campo e nas conversas com os moradores do Andaraí onde inúmeros questionamentos também começam a ganhar força. Os mesmos moradores que celebraram a chegada da UPP no Morro apontam as limitações do programa:

Morador: Mas quando veio a UPP para o morro do Andaraí, em 2010, já tinha uma grande propaganda em torno do programa. Então alguns moradores começaram a ver a chegada da UPP no Morro do Andaraí como um benefício do Estado, uma salvação, como um arrebentar de correntes. O que não foi, efetivamente não foi. O que o Estado oficial nos dizia era o seguinte: "Queremos livrar essa população da truculência dos bandidos." Mas nós trocamos a truculência dos bandidos, pela da polícia. (Morador 2, 45 anos).
As inúmeras alterações do cotidiano sentidas pelos moradores passam a expor as fragilidades do arranjo proposto pela ocupação que pressupõe uma integração entre a favela e as forças da ordem. A maneira como têm sido resolvidas as rotinas a partir da UPP, principalmente, a partir da imposição de determinações das forças policiais do Estado configura-se em flagrante tentativa de policialização da vida. A percepção de um controle maior dos momentos de sociabilidade, com os policiais excedendo suas atribuições e interferindo diretamente nas rotinas diárias, motiva grande parte das discussões públicas e vem se caracterizando como um dos principais entraves à aceitação da presença policial no território.

Um dos exemplos mais recorrentes do questionamento desse controle é verificado quando os moradores relatam suas implicações na maneira como se divertem e ocupam o espaço público na favela.

Como nas outras favelas ocupadas, no Andaraí, a organização de atividades públicas deve passar pelo crivo do comando da UPP. Para tal, os moradores que se dispõem a organizar qualquer atividade cultural ou esportiva, devem solicitar autorização, por meio de documento padrão disponibilizado pela força de segurança pública.

Como uma espécie de polícia do comportamento, a UPP atua na supervisão das ações dos sujeitos, principalmente, dos mais jovens. Como relata uma moradora:

Moradora: "[...] é tipo assim: tem um bar lá na rua Leopoldo, em frente aonde eu moro, bar do Bolinha. Lá todo domingo ele colocava um funk pra toda rapaziada. Os UPP limitaram a hora, limitaram algumas coisas que a gente não pode ouvir, não deixam ouvir". (Moradora 3, 25 anos).

Não apenas os espaços públicos de divertimento da comunidade vêm sendo controlados pelos policiais, há relatos de que os espaços privados das festas de família também sofrem ingerência das determinações da UPPs:

Morador: "[...] hoje em dia, também acontece uma coisa dentro da comunidade: muitas das vezes você está dentro da sua casa fazendo uma festa, não que seja uma coisa desorganizada, mas, muitas vezes o policial vem e quer 
acabar com a festa na sua casa". (Morador 4, 30 anos).

Não obstante as críticas ao controle dos eventos públicos, os moradores mais velhos, aparentemente, admitem que haja certa regulação da esfera pública em troca da sensação de segurança atribuída ao cerceamento dos conflitos entre as quadrilhas de traficantes locais e seus rivais que intentavam tomar o controle do morro e entre estes e a polícia. Isto se reflete em algumas falas:

Morador: "Pelo menos lá na comunidade do Andaraí os que não tinham muita regra estão se domesticando mais, porque até então, antes, podia tudo, ninguém respeitava nada". (Morador 5, 53 anos).

Morador: "Eu acho que agora, em parte é até melhor, a pessoa vai, se diverte. A pessoa chega numa certa idade como eu tô e vai num ambiente que você não quer ver mais briga. Hoje em dia se tem uma briga, a pessoa está se conscientizando: "pô não briga não, chama a polícia"' (Morador 6, 60 anos).

Entretanto, como toda produção da vida social é permeada por consensos e dissensos, a provável aceitação do controle em troca de segurança demonstra-se não tão alicerçada no senso comum local. Se antes era possível ver traficantes transitando pela comunidade com seus fuzis, plantados nos postos de observação ou nas bocas de fumo, locais de varejo da droga. Agora, com a UPP, vê-se durante todo o dia viaturas policiais estacionadas nos diversos acessos à comunidade, bem como rondas extensivas com policiais empunhando fuzis em todas as ruas e becos. Esta ostensividade tem como objetivo claro a tentativa de demonstrar que o controle do território mudou de mãos.

A ausência do narcotráfico não é, todavia, uma certeza apontada pelos moradores. Ao contrário, os relatos apontam para a constatação de que a presença dos traficantes e seu comércio, apesar de discretos, ainda são comuns. Quando perguntados sobre isso os moradores logo relatam que:

Morador: "[...] os caras de antes ainda estão por aqui mas escondidos, só que continuam e agora com a UPP não tem risco de confronto". (Morador 7, 34 anos)
Moradora: "[...] onde tem UPP, não tem o risco de invasão de outra facção, então isso gera uma tranquilidade, para o outro lado, que não tem risco de invasão..." (Moradora 8, 22 anos).

\section{“É mais polícia e menos governo"}

No enredo proposto pela Secretaria de Segurança do Estado do Rio de Janeiro para a implantação de uma UPP - decreto $n^{\circ}$. 42.787, de 06 de janeiro de 2011 - consta em sua "Etapa III - Implantação da UPP" que, após a acomodação definitiva dos policiais na comunidade, há a preparação desta "para a chegada de outros serviços públicos e privados que possibilitem sua reintegração à sociedade democrática".

Este seria, portanto, o momento em que, com a ausência do poderio dos traficantes, a comunidade voltaria a receber plenamente os serviços públicos e as ações sociais anteriormente deficitárias, mas parece que no Morro do Andaraí as coisas parecem não ser bem assim:

Pesquisador: $E$ os serviços públicos melhoraram?

Moradora: A ideia inicial era maravilhosa né, a ideia inicial poxa, bacana, você vai dar uma faxina na comunidade, né? Diziam que iam injetar $\mathrm{N}$ coisas na comunidade, mas é delicado, que nem eu te falei, as coisas chegam, mas chegam pela metade, já chegam falhas, e a própria comunidade nem sabe fazer uso daquilo que chega, não sabe dar valor, àquilo que chega (Moradora 9, 36 anos).

Assim como ocorreu com o desapontamento gerado em relação a continuação do controle de suas ações cotidianas, a esperança de um fortalecimento nas ações sociais e nos serviços públicos oferecidos pelo governo na comunidade começa a esmorecer entre os moradores do Morro do Andaraí:

Morador: "[...] a verdade é que o governo pensa que é só a presença da polícia que é governo, só que muitas outras coisas que são governo também eles foram tirando da comunidade ao longo do tempo, o governo foi saindo e abandonando a comunidade sem governo" (Morador 4, 30 anos). 
Como aponta Neves (1994), o Estado atuando, em muitos momentos, à margem dos textos constitucionais legais, impede a integração jurídica e igualitária na sociedade, isto é, a ancoragem do direito no indivíduo independente de suas condições de classe e de sua posição na estratificação sociocultural.

A avaliação de Neves corrobora com a constatação de que a precária autonomia do sistema institucional das UPPs conduz ao tratamento desigual dos cidadãos perante a lei, como sempre tem sido em relação aos moradores de favelas.

Mesmo em tempos de "pacificação" permanece nas favelas ocupadas aquilo que o autor diagnosticou como a subcidadania brasileira, caracterizada pela subintegração e a sobreintegração dos cidadãos. O primeiro grupo de subcidadãos, destituídos do acesso aos benefícios do ordenamento jurídico, possui mais deveres que direitos. Já o segundo é composto pelos privilegiados sobrecidadãos que podem dispor da burocracia estatal para fazer valer seus interesses (NEVES, 1994).

A comprovação empírica das avaliações de Neves é apresentada por um dos moradores:

Morador: "A gente sabe que há por parte do governo, por parte da visão econômica, e do faturamento, a visão de estarmos seguros até esse período das Olimpíadas, aí, a gente chega em uma conclusão que a UPP, ela passa ser uma polícia de patrimônio, ela não é uma polícia que defende o direito do cidadão, ela ainda está em função do movimento de faturamento da cidade, não de ajudar a melhorar nossa vida aqui. Então, a mudança que a gente esperava é que a UPP fosse de fato uma polícia que assegurasse o direito do cidadão, que ajudasse a fortalecer nosso acesso aqui dentro às políticas sociais e não que tenha uma visão como da outra polícia que assegura o patrimônio da classe social mais alta". (Morador 10, 54 anos).

$\mathrm{Na}$ avaliação, o morador reflete o profundo desapontamento da comunidade ao constatar que a UPP - anunciada como um mecanismo de atração de ações sociais e políticas públicas para a comunidade - em muitos momentos termina por reproduzir as práticas patrimoniais, tão comuns em suas ações no restante da cidade.

\section{Nem tão próxima assim - À guisa de conclusão}

O Rio de Janeiro está no centro do que acontece no país e a atenção dada a tudo que aqui ocorre não é diferente, dando certo ou não, governos de outros Estados se apropriam de iniciativas desenvolvidas em território fluminense. Cabe, portanto, a todos aqueles que se interessam pela construção de alternativas democráticas ao combate da violência a tarefa de se debruçar sobre tais questões e apontar acertos e lacunas.

O Estado vem se utilizando, a partir UPPs, da estratégia de estabelecer um contato mais próximo com as comunidades, o qual tem denominado como policiamento de proximidade. Mesmo que não haja uma formulação oficial a respeito do que significaria para o Governo do Estado e para a Secretaria de Segurança o policiamento de proximidade, infere-se que haja uma tentativa de apropriação de conceitos que tratam do tema.

As representações sociais dos moradores do Morro do Andaraí a respeito da atuação da UPP fazem pensar algumas disjuntivas entre a efetivação desta modalidade de policiamento no Morro e a práxis dos policiais envolvidos no trabalho cotidiano.

O entrave para a apropriação e efetivação de um policiamento comunitário pelos policiais está justamente na cabeça destes sujeitos, ou seja, não adianta uma pretensa filosofia da ação integradora da polícia se o comportamento apreendido pelos operadores é o de policiar as comunidades tidas como perigosas e sua gente (DA SILVA, 2003).

Os relatos anteriores em relação à atuação coercitiva dos policiais sustentam a visão difundida de que com as populações dos territórios da pobreza, o emprego da força é a melhor alternativa. Mas a força coercitiva não se manifesta apenas no controle das rotinas, a dificuldade de diálogo entre os policiais da UPP e os moradores é outro marcador da incapacidade de o programa de pacificação integrar as favelas aos mesmos direitos experimentados no asfalto.

O controle da sociabilidade local é a mancha mais facilmente identificável no fardamento da UPP. De maneira contundente, Batista (2011) argumenta que nos territórios "pacificados" estaria se consolidando uma "gestão policial da vida", pois, ocupando militarmente, o Estado desloca 
sua atenção do social (gestão coletiva de projetos de vida, oferecimento de serviços e fortalecimento da cidadania) para o gerenciamento penal da pobreza.

Parece-nos, concluindo este trabalho, que o Poder Público, deveria buscar, através de ações de políticas públicas que articulassem segurança e cidadania, apoiar, induzir e respeitar o reflorescimento das sociedades civis locais, dizimadas nas favelas e isoladas pelo medo e pela desconfiança. Somente a partir de iniciativas de desenvolvimento local, com o fortalecimento de laços de solidariedade comunitária, experiências verdadeiramente emancipatórias poderão ocorrer, produzindo autonomia, desenvolvimento e bem-estar para a população.

\section{Referências}

BATISTA, V. M. O Alemão é muito mais complexo. Texto apresentado no $17^{\circ}$ Seminário Internacional de Ciências Criminais em São Paulo, São Paulo, 23 jul. 2011.

BOURDIEU, P. O Poder Simbólico. 15ª . ed. Rio de Janeiro: Bertrand Brasil, 2011.

BURGOS, M. B. Dos Parques Proletários ao FavelaBairro: as políticas públicas nas favelas do Rio de Janeiro. In: ZALUAR, A. E. A. M. (. ). Um Século de Favela. Rio de Janeiro: FGV, 2006.

CANO, I.; BORGES, D.; RIBEIRO, E. Os Donos do Morro: Uma Avaliação Exploratória do Impacto das Unidades de Polícia Pacificadora (UPPS) No Rio de Janeiro. Rio de Janeiro: Heinrich Boll Stiftung, 2014.

CASTRO, R. V. O Quarto de Getúlio: representações e memória na política brasileira. In: SÁ, C. P. D. (. ). Memória, imaginário e representações sociais. Rio de Janeiro: Editora Museu da República, 2005.

CASTRO, R. V. D. Relatos de viagens, pensamento social e representações sobre o Brasil e os brasileiros [mimeo], 2015.

DA SILVA, J. Segurança pública e polícia: Criminologia crítica aplicada. $1^{\text {a }}$. ed. Rio de Janeiro: Forense, 2003.

DA SILVA, J. Violência e Identidade Social: Um Estudo Comparativo sobre a Atuação Policial em duas Comunidades no Rio de Janeiro. Rio de Janeiro: Tese (Doutorado) - PPCIS/UERJ, 2005.
DA SILVA, J. Favelas e Violência no Rio: sem conflitos, entre o sonho e o pesadelo da apartação. In: MELLO, M. A. D. S., et al. Favelas cariocas ontem e hoje. Rio de Janeiro: Garamond, 2012. p. 393-413.

DA SILVA, J. Militarismo. In: SANSONE , L.; FURTADO, C. A. Dicionário crítico das Ciências Sociais dos países de fala oficial portuguesa. Salvador: EDUFBA, 2014. p. 349-362.

DAVIS, M. Planeta Favela. São Paulo: Boitempo, 2006.

DOUGLAS, M. Pureza e Perigo. 2a . ed. São Paulo: Perspectiva, 2014.

FLEURY, S. Militarização do social como estratégia de integração - o caso da UPP do Santa Marta. Sociologias, Porto Alegre , p. 194-122, Mai/Ago 2012.

FOUCAULT, M. Vigiar e punir: nascimento da prisão. Petrópolis: Vozes, 2009.

FREYRE, G. Casa-Grande \& Senzala. São Paulo: Global Editora, 2005.

FRIDMAN, L. C. Delegação de poder discricionário: O sonho de paz. DILEMAS: Revista de Estudos de Conflito e Controle Social, Rio de Janeiro, v. 7, p. 611-623, Out/Nov/Dez 2014. ISSN 4.

GONÇALVES, R. S. Favelas do Rio de Janeiro. Rio de Janeiro: Pallas: Ed. PUC-Rio, 2013.

HERZLICH, C. A Problemática da Representação Social e sua Utilidade no Campo da Doença. PHYSIS - Revista de Saúde Coletiva, Rio de Janeiro, v. 15(suplemento), p. 57-70, 1991.

HOLANDA, S. B. D. Raízes do Brasil. São Paulo: Companhia das Letras, 1995.

JODELET, D. Representações sociais: um domínio em expansão. In: JODELET, D. As representações sociais. Rio de Janeiro: EdUerj, 2001.

JODELET, D. Loucuras e representações sociais. Rio de Janeiro: EdUerj, 2005.

JOVCHELOVITCH, S. Representações sociais e esfera pública: a construção simbólica dos espaços públicos no Brasil. Petrópolis: Vozes, 2000.

JOVCHELOVITCH, S. Os contextos do saber: representações, comunidade e cultura. $2^{\mathrm{a}}$. ed. Petrópolis: Vozes, 2011.

KAZTMAN, R. Seducidos y abandonados: EI aislameinto social de los pobres urbanos. Revista de la CEPAL, n. 75, p. 171-189, dez 2001. 
LEEDS, A.; LEEDS, E. A Sociologia do Brasil urbano. Rio de Janeiro: ZAHAR Editores, 1978.

LEEDS, E. Cocaína e poderes paralelos na periferia urbana brasilera: ameaças à democratização em nível local. In: ZALUAR, A.; ALVITO, M. Um Século de Favela. Rio de Janeiro: Fundação Getúlio Vargas, 2006. p. 233-276.

LEITE, M. P. Entre a 'guerra' e a 'paz': Unidades de Polícia Pacificadora e gestão dos territórios de favela no Rio de Janeiro. DILEMAS: Revista de Estudos de Conflito e Controle Social, Rio de Janeiro, v. 7 , n. 4, p. 625-642, Out/Nov/Dez 2014.

MACHADO DA SILVA, A. Sociabilidade Violenta: Uma Dificuldade a mais para a Ação Coletiva nas Favelas. In: IBASE Rio a Democracia Vista de Baixo. Rio de Janeiro: IBASE, 2004. p. 33-44. Disponivel em: <http://www.ibase.br/pt/wp-content/uploads/2011/06/ cter-a-democracia-vista-de-baixo.pdf $>$.

MACHADO DA SILVA, L. A. (. ). Vida sob cerco: violência e rotina nas favelas do Rio de Janeiro. Rio de Janeiro: Nova Fronteira, 2008.

MACHADO DA SILVA, L. A. A continuidade do "problema favela". In: OLIVEIRA, L. L. Cidade: história e desafios. Rio de Janeiro: FGV, 2002.

MARICATO, E. Globalização e política urbana na periferia do capitalismo. In: RIBEIRO, L. C. D. Q.; JUNIOR, O. A. D. S. As metrópoles e a questão social brasileira. Rio de Janeiro: Revan, 2007.

MINAYO, M. C. D. S. O Conceito de Representações Sociais dentro da Sociologia Clássica. In: GUARESCHI, P.; JOVCHELOVITCH , S. Textos em Representações Sociais. Petrópolis: Vozes, 2012. p. 73-92.

MISSE, M. Malandros, marginais e vagabundos e a acumulação social da violência no Rio de Janeiro. (Tese de Doutorado). Rio de Janeiro: IUPERJ, 1999.

MOSCOVICI, S. La Psychanalyse: Son image et son public. Paris: PUF, 1961/1976.

MOSCOVICI, S. A Representação Social da Psicanálise. Rio de Janeiro: Zahar, 1978.

MOSCOVICI, S. Representações Sociais: investigações em psicologia social. Petrópolis: Vozes, 2011.

NEDER, G. Cidade, Identidade e Exclusão Social. Tempo, Rio de Janeiro, v. 2, n. 3, p. 106-134, 1997.

NEVES, M. Entre Subintegração e Sobreintegração: A Cidadania Inexistente. DADOS-Revista de Ciências
Sociais, Rio de Janeiro, v. 37, p. 253-276, 1994. ISSN 2.

SÁ, C. P. A teoria do núcleo central das representações sociais. In: SÁ, C. P. Núcleo central das representações sociais. Petrópolis: Vozes, 2002.

SOUSA, J. Ralé brasileira: quem é e como vive. Belo Horizonte: UFMG, 2009.

VALLADARES, L. A Gênese da Favela Carioca. A Produção Anterior às Ciências Sociais. Revista Brasileira de Ciências Sociais, v. 15, n. 44, out. 2000.

WAGNER, W. Sócio-Gênese e Características das Representações Sociais. In: MOREIRA, A. S. P.; OLIVEIRA, D. C. Estudos Interdisciplinares de Representação Social. 2a . ed. Goiânia: AB, 2000. p. 328.

ZALUAR, A.; ALVITO, M. Um século de Favela. $5^{a}$. ed. Rio de Janeiro: FGV, 2006. 